\title{
“Cirugía Percutánea" Historia, Presente y Perspectivas Futuras en Paraguay
}

\author{
"Percutaneous Surgery" \\ History, Present and Future Prospects in Paraguay
}

\author{
${ }^{\star a}$ María José Martínez Velázquez ${ }^{1},{ }^{\star b}$ Rosa Irene Sánchez Alvarenga ${ }^{1,2}$, \\ ${ }^{\star * a}$ Andrada José ${ }^{,},{ }^{\star *}$ Filartiga Anibal ${ }^{1}{ }^{* \star c}$ Parquet Guido ${ }^{1,2},{ }^{\star \star d}$ Suarez Anzorena Francisco ${ }^{3}$, \\ ${ }^{\star *}$ Calvo Villalba Miguel ${ }^{4}$
}

\begin{abstract}
1. Universidad Nacional de Asunción, Hospital de Clínicas, Cirugía General, Primera Cátedra de Clínica Quirúrgica, Sala X. San Lorenzo, Paraguay 2. Instituto de Previsión Social, Hospital Central, Servicio de Cirugía Mínimamente invasiva. Paraguay

3. Universidad de Buenos Aires, Facultad de Medicina, Hospital de Clínicas José de San Martin. Argentina 4. Instituto Radiológico Calvo. Asunción - Paraguay
\end{abstract}

\section{RESUMEN}

El fin de este trabajo es dejar precedentes del inicio y evolución de la cirugía percutánea en nuestro país ya que se ha convertido en un arma más que ofrecer al paciente, probablemente una de las intervenciones más beneficiosas en términos de complicaciones y altas tasas de buenos resultados. El inicio en el país data desde 1981 siendo prácticamente paralela al inicio a nivel mundial de estas técnicas. Actualmente esta técnica se encuentra ampliamente aceptada y se practica en centros públicos, del interior y la capital, así como en centros privados.

Palabras clave: cirugía percutánea, Paraguay, drenaje.

\section{ABSTRACT}

The purpose of this work is to set precedents of the beginning and evolution of percutaneous surgery in our country, since it has become one more weapon to offer to our patients, probably one of the most beneficial interventions in terms of complications and high rates of good results. The beginning in the country dates from 1981 being practically parallel to the beginning of these techniques worldwide. Currently this technique is widely accepted and is practiced in public centers, in rural areas and the capital, as well as in private centers.

Keywords: percutaneous surgery, Paraguay, dreinage.

\section{INTRODUCCIÓN}

En medicina, el conocimiento propio y sin compartir es estéril. No se puede realizar ningún procedimiento sin conocer los pasos previos, incluso los fallidos, de antecesores que lo realizaron. El tratamiento hoy en día tiende a ser cada vez menos agresivo e invasivo.

La cirugía mínimamente invasiva - representada por la cirugía endoscópica, la videolaparoscopia y la cirugía percutánea - se ha incorporado al arsenal terapéutico en los últimos años. De estas tres ramas, la menos conocida es la cirugía percutánea, también conocida como intervencionismo guiado por imágenes o radiología intervencionista ${ }^{(1)}$.

El siglo XX comenzó con el descubrimiento y rápida difusión de los rayos X, lo que le valió a W. Röentgen el primer premio Nobel de Física, en 1901. Rápidamente se comenzaron a descubrir las aplicaciones en medicina: en 1927, Egas Moniz describió la angiografía cerebral y en 1929 Forssmann realizó, en su propia persona, la primera ventriculografía. Tras el parén-

\footnotetext{
* Autores

a. Residente de Cirugía General - Primera Catedra de Clínica Quirúrgica - Sala X - Facultad de Ciencias Médicas - Universidad Nacional de Asunción. Paraguay

b. Docente de la Primera Cátedra de Clínica Quirúrgica - Sala X - Facultad de Ciencias Médicas - Universidad Nacional de Asunción. Médico cirujano del Servicio de Cirugía Mínimamente invasiva - Hospital Central IPS. Paraguay

** Coautores

a. Cirujano General de la Primera Cátedra de Clínica Quirúrgica - Sala X - Facultad de Ciencias Médicas - Universidad Nacional de Asunción. Paraguay

b. Profesor y Ex Decano de la Facultad de Ciencias Médicas - Universidad Nacional de Asunción. Paraguay

c. Docente de la Cátedra de Anatomía - Facultad de Ciencias Médicas - Universidad Nacional de Asunción. Jefe del Servicio de Cirugía Mínimamente invasiva - Hospital Central IPS. Paraguay
}

d. Docente del Hospital de Clínicas José de San Martin-Facultad de Medicina - Universidad de Buenos Aires - Argentina

e. Médico especialista en imágenes del Instituto Radiológico Calvo. Asunción - Paraguay

Autor Correspondiente: María José Martínez Velázquez - Email: majomave93@hotmail.com

Recibido: 30-09-2020 - Aceptado: 22/10/2020

Este es un artículo publicado en acceso abierto bajo una licencia Creative Commons 
tesis de la II Guerra Mundial se pusieron los cimientos de lo que veinte años más tarde se conocería, en un primer momento, como "Radiología Vascular", a la que se añadiría el término "Intervencionista" a principios de los 80. Los doctores Charles Dotter, Cesare Gianturco, Joseph Rösch, y Kurtz Amplatz aportaron las ideas; fue el tiempo de los pioneros. Sin embargo, faltaban todavía algunos años para que la tecnología de la imagen y de los materiales permitieran hacer posible sus ideas. El doctor Seldinger, 1953, describió el acceso no quirúrgico a cualquier territorio vascular, lo que permitió la realización de la mayoría de técnicas percutaneas que se llevan a cabo hoy día ${ }^{(2)}$.

La cirugía percutánea $(\mathrm{CP})$ es un procedimiento quirúrgico, a través de la piel, que por una pequeña herida operatoria se accede hasta una colección localizada, en cavidad abdominal o tórax, con contenido líquido, infectada o no, purulenta o necrosada. La intención primaria de esta es diagnosticar y/o tratar drenando una colección, sin contaminar el resto de la cavidad y ofreciendo el mismo resultado terapéutico que una cirugía a cielo abierto.

Probablemente el primer uso percutáneo de una aguja de aspiración/drenaje fue a mediados de 1950. De hecho, en el British Journal of Surgery en 1954, se describió "aspiración de absceso hepático con aguja fina” como un tratamiento curativo ${ }^{(3)}$.

La falta de evolución rápida en la parte imagenologica predispuso a la poca evolución de la cirugía percutánea hasta 1970. Sin embargo, Pedersen y un grupo describió el uso del ultrasonido para drenar un absceso renal en $1973^{(4)}$. También Hans Holm describió el uso de la ecografía para punciones guiadas en distintas estructuras para biopsias y aspiración ${ }^{(5)}$. Smith y Bartrum reportaron el uso del ultrasonido para la guía en drenaje de abscesos en 1974 en el American Journal of Roentgenology (AJR) $)^{(6)}$.

A pesar de estos reportes de drenajes de abscesos guiados por ecografía, fue el advenimiento de la tomografía la que revoluciono este procedimiento. Inicialmente en Estados Unidos por Gerzof, Haaga, Karlson, Martin, Van Sonnenberg, Ferrucci y Mueller, numerosos artículos fueron publicados en 1980 donde se establecían técnicas, resultados, complicaciones y controversia de este procedimiento ${ }^{(7,8,9,10,11,12)}$.

El artículo publicado por Gerzoff et al., que fue publicado en el NEJM en septiembre de 1981 probablemente fue el articulo más importante y que dio pie a la mayor utilización de estos procedimientos para evitar la cirugía a cielo abierto, reportando su experiencia durante 5 años $^{(13)}$.

Es difícil imaginar el escepticismo de cambiar una cirugía por un drenaje percutáneo hace 37 años. La idea se fue esparciendo hasta llegar a nuestro país en 1980 aproximadamente de la mano de grandes maestros de la cirugía paraguaya.

En este trabajo queremos dejar precedentes del inicio y evolución de la cirugía percutánea en nuestro país ya que se ha convertido en un arma más que ofrecer al paciente, probablemente una de las intervenciones más beneficiosas en términos de complicaciones y altas tasas de buenos resultados. Por lo cual vale la pena realizar una retrospectiva histórica y darse cuenta del porque la cirugía percutánea se volvió un procedimiento tan fundamental en la práctica médica diaria.

\section{MATERIAL Y MÉTODO}

Estudio retrospectivo, de cohorte histórico, observacional descriptivo.

Se enumeran retrospectivamente aportes y/o enunciados de relatos desde 1981 hasta la fecha, presentados en entrevistas escritas a cirujanos referentes a nivel país.

\section{RESULTADOS}

La evolución a nivel nacional de la cirugía percutánea se remonta a 1981, el Dr. Anibal Filartiga retornaba posterior a pasar unos años en el hospital Memorial de Nueva York donde vio y asistió en varias tomas de biopsias pulmonares guiadas por radioscopia, a su llegada al país realizo su primera biopsia de un tumor pulmonar guiado por radioscopia ${ }^{(14)}$. En 1982 donde el Dr. José Andrada realiza el primer drenaje de dos colecciones a nivel de parietocolico izquierdo y derecho bajo guía ecográfica.

Los drenajes percútanos del abdomen fueron desarrollándose paralelamente a la evolución de los drenajes. El Pig tail y la autofijación fueron decisivos. La colocación segura por técnica de Seldinger o por trocar abrieron el camino de forma permanente. "La última cirugía de drenaje por la técnica extra-peritoneal de Ochsner DeBakey, de un absceso hepático, que efectúe, data de los 90". Refiere el Dr. José Andrada. A partir de allí todas fueron percutáneas. La Gastrostomía Endoscópica Percutánea o PEG, sustituyó a la gastrostomía quirúrgica de alimentación enteral de 1.948. Desde su aparición en los 80, y su auge desde los 90, prácticamente borraron el acto quirúrgico a cielo abierto a excepción de algunos casos donde el medio no lo permita.

En los años siguientes aumenta el uso de drenajes percutáneo, biopsias guiadas por ecografía, radioscopia y tomografía. Ya que estos procedimientos presentaban menor dolor post operatorio. La recuperación es más rápida post procedimiento, el cual se puede realizar ya sea en sala de operaciones, UTI, sala de imágenes o propia cama del paciente ya que en la mayoría de los casos se realiza con anestesia local.

La cirugía percutánea no solo es ámbito de los cirujanos, si nos remontamos a la historia podemos ver que también tuvo sus orígenes en la radiología intervencionista. A nivel nacional el Dr. Miguel Calvo, quien ser formo en la Facultad de Ciencias Médicas y realizo su especialización en Bélgica, retorno al país en 1998 y en el mismo año realiza su primer drenaje biliar externo interno en el país.

La creación del primer y único servicio de Cirugía Mínimamente invasiva del país se remonta al 2006, en el Instituto de Previsión Social (actualmente Hospital Central de IPS) donde se designa al Dr. Guido Parquet como Jefe del servicio. El cual se formó en la I Catedra de Clínica Quirúrgica - Sala X del Hospital de Clínicas, luego realizo un fellow de cirugía gastroenterológica en Estados Unidos y realizo 2 años de entrenamiento en cirugía percutánea en el Hospital de Clínicas José de San Martin, hospital escuela de la Universidad de Buenos Aires. Actualmente se encuentra hasta la fecha a la cabeza de dicho departamento y se mantiene como único a nivel País.

En el servicio de cirugía mínimamente invasiva se realiza drenajes de abscesos abdominales, abscesos hepáticos, punciones diagnósticas guiadas, drenajes paliativos de vía biliar, cole- 
cistostomias, yeyunostomias y gastrostomías entre otros, refiere el Dr. Parquet. Son prácticas diarias, ya que con el correr del tiempo tiene más adeptos y menos detractores por todos los beneficios que representa la cirugía percutánea.

En el 2001 al regresar del entrenamiento en Buenos Aires, el Dr. Guido Parquet inicio en la I Catedra de Clínica quirúrgica, con la aprobación de Dr. Anibal Filartiga Lacroix, jefe del servicio en el momento, a implementar mayores procedimientos percutáneos guiados por imágenes auxiliares, los cuales iban ganando mayor aceptación a nivel institucional.

Tal fue la aceptación de dichos procedimientos que en el 2002 durante el XVI Congreso Paraguayo de cirugía, se realizó el primer curso pre congreso de ecografía para cirujanos en las instalaciones de la I Catedra de Clínica Quirúrgica - Sala X, en el antiguo Hospital de Clínicas, ubicado en Sajonia. Este congreso estuvo bajo la presidencia del Dr. Anibal Filartiga, y la dirección científica del Dr. Francisco Suarez Anzorena, actual jefe del departamento de intervencionismo en el Hospital de Clínicas José de San Martin, y el Dr. Parquet en la dirección general. Desde ese año y todos los siguientes se hizo tradicional el curso de ecografía pre o intra congreso para cirujanos y con el correr del tiempo se fueron agregando punciones básicas y drenajes dentro del mismo.

Los lazos creados con el Dr. Francisco Suarez Anzorena permitieron que más cirujanos realicen un entrenamiento en cirugía percutánea en su servicio. Entre los que caben destacar a la Dra. Rosa Sánchez, la Dra. Ma. Liz Sánchez, el Dr. Fernando Heiberger y el Dr. Roberto Duarte.

Existiendo únicamente el servicio de cirugía mínimamente invasiva en el IPS, se realizó un proyecto para la creación del "Departamento de Cirugía Mínima Invasiva en el Hospital de Clínicas” por parte del Dr. Parquet, Dra. R. Sánchez, Dra. M. Sanchez y el Dr. Heiberger el cual fue aprobado por resolución 837/2012 del Consejo Directivo de la Facultad de Ciencias Médicas el 28 de noviembre el 2012. Pese a la aprobación del proyecto, actualmente se sigue sin contar con dicho servicio.

Y en el 2013, finalmente, durante el periodo del Dr. Filartiga, se realiza el primer curso de intervencionismo en las instalaciones de la Catedra de Anatomía Descriptiva y Topográfica con el Dr. Luis Bogado Yinde como jefe de Catedra y el Prof. Castor Samaniego como jefe de servicio de la I Catedra de Clínica Quirúrgica. Contando con el Dr. Francisco Suarez Anzorena como director científico, al Dr. Parquet como director general y a la Dra. Rosa Sánchez como coordinadora general. En este curso se desarrollaron técnicas avanzadas de intervencionismo vascular, percutáneo y endoscópico. Estas últimas con la colaboración del Dr. José Avila y el Dr. Félix Ibieta.

Desde hace aproximadamente 15 años funciona la Fundación Triada Mínima Invasiva en la ciudad de Pilar, Buenos Aires, cuyo objetivo es la docencia, asistencia, desarrollo e investigación de procedimientos mínimamente invasivos utilizados para el diagnostico y tratamiento de enfermedades, donde anualmente se reúnen cirujanos de la Argentina,
Uruguay y Paraguay. Allí se intercambian experiencias y casos sobre estos procedimientos.

\section{DISCUSIÓN}

El cirujano en su formación básica requiere estar actualizado debe estar entrenado en cirugía percutánea, formación en imágenes, ecografía, tomografía. Esto dará una formación integral para ofrecer a su paciente la mejor opción terapéutica posible. Cada uno debe conocer sus limitaciones y estar suficientemente preparado para poder ofrecer este manejo.

Actualmente en la formación del cirujano general se puede acceder a rotaciones por los servicios de gastroenterología o servicios de cirugía mínimamente invasiva ya sea en el país (IPS) o en el extranjero, ya que el único servicio de cirugía mínimamente invasiva es el de IPS como ya habíamos mencionado.

Los procedimientos percutáneos también se realizan en centros privados y públicos, tanto del interior como la capital.

A medida que la cirugía percutánea va ganando más adeptos por los beneficios que presenta, también se va haciendo más accesible con el avance de la tecnología. La limitación que presenta se basa en la disponibilidad de los materiales específicos para realizar estas cirugías y el costo de los mismos, que dependiendo del procedimiento, puede llegar a costar en nuestro país, lo mismo que una cirugía abierta.

"A grandes incisiones, grandes cirujanos", expresión atribuida a Guy de Chauliac (Francés) (1.260-1.308) debe pasar al merecido olvido.

\section{CONCLUSIÓN}

Los médicos no deberían tener miedo de adoptar técnicas guidas por imágenes, las cuales todos deberían aprender porque esto disminuye riesgos y complicaciones.

Los cirujanos deben aprender sobre radiología y los radiólogos, sobre cirugía, que probablemente fue una de las causas del poco desarrollo en las primeras etapas.

A medida que avanza el tiempo la tecnología es cada vez mayor y mejor, por lo cual estos procedimientos que tan intrincados con la imagen esta, irán mejorando y creciendo y cada vez se le dará mayor importancia y lugar en el campo quirúrgico. En vías biliares, páncreas, los stents esofágicos, gástricos, colónicos, biliares, son ahora las primeras opciones en el arsenal terapéutico. Sólo que aún presentan un costo muy alto en nuestro medio; sin embargo en lugares como Europa o América del Norte estos son más accesibles que cirugías a cielo abierto. Por lo que en nuestro país se divide bastante la población que tiene acceso a estos tratamientos, aunque con el correr del tiempo esperemos esto no sea una barrera.

El manejo multidisciplinario de los pacientes, uniendo todas las técnicas mínima invasivas, asegura la buena evolución de los mismos.

Primero no dañar. "Primum non nocere”. Hipócrates. Cuanto menos lastimemos al paciente en el sublime acto de curar, mejores médicos seremos. 


\section{REFERENCIAS BIBLIOGRÁFICAS}

1. Miranda C, Calvo M, Cuenca O. Cap 69. Procedimientos percutáneo. En: Villalba J, Morales R. Cirugía: Fundamentos y Terapéutica. Editorial de la Facultad de Ciencias Médicas de la UNA (EFACIM). Asunción; 2001: 529-31.

2. Maynar M. Cap 1. Historia, estado actual y tendencias. En: Carnevale F. Radiologia intervencionista e cirurgia endovascular. Thieme Revinter. Brazil 2017. 8-9.

3. McFadzen AJS, Chang KPS, Wong CC. Solitary pyogenic abscess of the liver treated by closed aspiration and antibiotics. A report of 14 consecutive cases with recovery. Br J Surg 1954; 41 :141-52.

4. Pedersen JF, Hancke S, Kristensen JK. Renal carbuncle: antibiotic therapy governed by ultrasonically guided aspiration. J Urol. 1973; 109 (5): 777-8. doi:10.1016/s0022-5347(17)60541-x

5. Holm HH, Kristensen JK, Rasmussen SN, Northeved A, Barlebo H. Ultrasound as a guide in percutaneous puncture technique. Ultrasonics. 1972;10(2):83-6. doi:10.1016/0041-624x(72)90252-1

6. Smith EH, Bartrum RJ Jr: Ultrasonically guided percutaneous aspiration of abscesses. AJR 1974; 122 (2): 308-12.

7. Gerzof SG. Triangulation: indirect CT guidance for abscess drainage. $A J R$ Am J Roentgenol. 1981;137(5):1080-1. doi:10.2214/ajr.137.5.1080
8. Haaga JR, Alfidi RJ, Havrilla TR, et al. CT detection and aspiration of abdominal abscesses. AJR Am J Roentgenol.1977;128(3):465-74. doi:10.2214/ajr.128.3.465

9. Haaga JR, Alfidi RJ, Cooperman AM, Havrilla R, Meaney TF, Ockner SA, Stiff P, Silver S (1976) Definitive treatment of a large pyogenic liver abscess by CT guidance. Cleve Clin Q 43:85-8.

10. Karlson KB, Martin EC, Fankuchen EI, et al. Non-surgical drainage of intra-abdominal and mediastinal abscesses: A report of twelve cases. Cardiovasc Intervent Radiol 1981; 4: 170-6. Doi: 10.1007/BF02552419

11. VanSonnenberg E, Ferrucci JT Jr, Mueller PR, Wittenberg J, Simeone JF. Percutaneous drainage of abscesses and fluid collections: technique, results, and applications. Radiology. 1982; 142 (1): 1-10. doi: 10.1148/radiology.142.1.7053517

12. Mueller PR, van Sonnenberg E, Ferrucci JT Jr (1984) Percutaneous drainage of 250 abdominal abscesses and fluid collections. Part II: Current procedural concepts. Radiology 151:343-7.

13. Gerzof SG, Robbins AH, Johnson WC, Birkett DH, Nabseth DC Percutaneous Catheter Drainage of Abdominal Abscesses - A FiveYear Experience. N Engl J Med 1981; 305 (12): 653-7 DOI: 10.1056/ NEJM198109173051201 